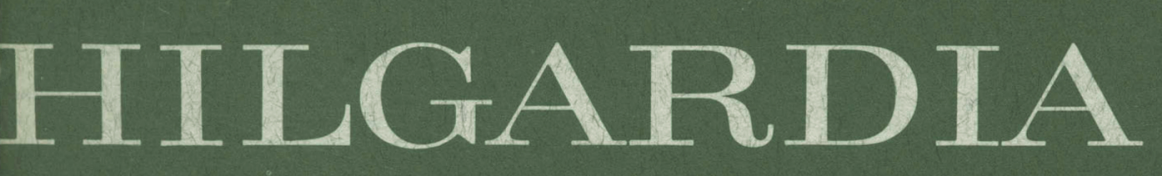

A JOURNAL OF AGRICULTURAL SCIENCE PUBLISHED BY THE CALIFORNIA AGRICULTURAL EXPERIMENT STATION

Volume 35, Number 2 - September, 1963

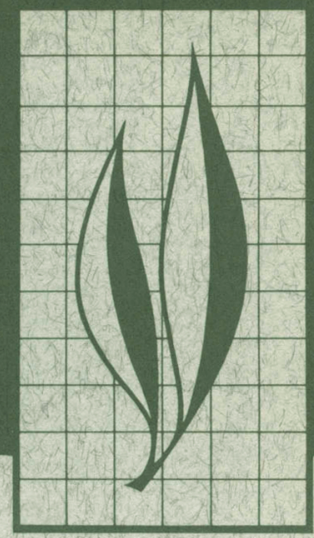

\title{
Problems in Evaluating Control of San Jose Scale with Spray Chemicals
}

E. M. Stafford and F. M. Summers 


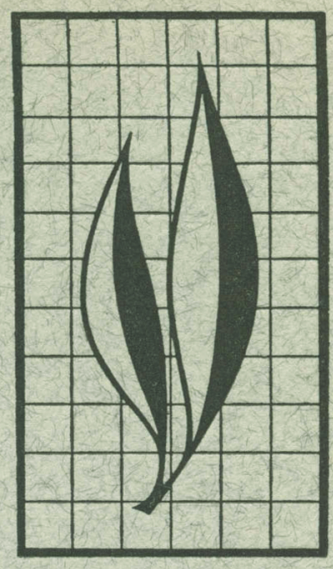

Problems of evaluating chemical control of San Jose scale are discussed on the basis of experiments in deciduous fruit orchards. Methods are described for sampling and counting scales for mortality determinations and for measuring the resurgence of a population after it has been reduced.

The methods used did not show conclusively any differences in performance among a number of the more effective insecticides used with oil in dormant or spring sprays. The methods were adequate to show that scale populations on peach trees do not increase as much in the growing season when trees are sprayed in May as when they are sprayed during fall or winter. On lightly infested peach trees sprayed in the dormant season or in May, the survivor progenies increased faster during the growing season than they did on trees that were more heavily infested when sprayed. The effects of variation in initial pest density on control were minimized by using pretreatment counts with the annual twig-count method. This method measured degree of population resurgence after treatment but did not show how numbers of survivors, effects of natural enemies, and other environmental factors acted together to produce the results observed. Sequences of samples for mortality determinations indicated trends in population change after treatment.

\section{THE AUTHORS:}

E. M. Stafford is Professor of Entomology and Entomologist in the Experiment Station, Davis. F. M. Summers is Professor of Entomology and Entomologist in the Experiment Station, Davis. 


\section{Problems in Evaluating Control of San Jose Scale with Spray Chemicals}

\section{INTRODUCTION}

SAN Jose SCALE (Aspidiotus perniciosus Comst.) has become increasingly prevalent in California, particularly since 1957. Research on control of this and other scale insects on stone fruits has been revived following development of many organophosphorus insecticides during the past 10 years.

The project reported here was begun in 1953 and continued to the present. Its objective was to find effective oilinsecticide mixtures that require less oil than conventional oil sprays. Such mixtures, it was hoped, would reduce the likelihood of oil injury and extend the range of performance against mites, aphids, and some species of moths. Adjustments in concentration of ingredients might also provide a wider choice of spray periods-fall, winter, late dormant, or summer.

No completely satisfactory experimental technique for measuring control of San Jose scale has yet been devised. Our main purpose in the present report is to show the problems encountered with particular materials and methods, in the hope of helping others to recognize those problems and plan their own work for meaningful results.

The difficulties in measuring control are those of design and operation of ex- periments. Each orchard selected must be assessed for kind of infestationeruptive or chronic, heavy or light, uniform or spotty. Some procedure must be devised for arranging trees in plots in such a way that between-plot variations in abundance and distribution of scale insects will be more nearly uniform. Information on distribution of the insects on each tree in an experiment might be used to estimate the potential of the infestation to cause damage. Where San Jose scale is very dense, the damage to certain parts of host trees is obvious, but the degrees of damage caused by lighter infestations are not easily distinguished. A common operation in experiments to control scales is the determination of mortality. A certain amount of time must elapse between application and evaluation in order to determine the full effect of the test sprays. This interim varies according to season and may also vary among insecticides. In the counting of scales, decisions on whether individual insects are alive, dead, or moribund are sometimes subjective. Furthermore, it has not been possible to separate the aftereffects of treatment from the effects of environment on population regeneration or resurgence.

\footnotetext{
${ }^{1}$ Submitted for publication February 15, 1963.
} 


\section{METHODS}

\section{Expression of Degree of Control}

The methods used by investigators for assessing control of San Jose scale and other scale insects have been concerned, for the most part, with scale mortality. Often the results of an insecticide treatment were measured by single post-treatment counts. Such counts have included either random or selective sampling of various parts of the host plants. Carman $(1956)^{2}$ used different parts of the host to measure different aspects of chemical control of the California red scale on citrus. Determination of mortality on individual scales may be either gross or limited on the basis of sex, stage of development, apparent cause of death, or other criteria. In control studies with armored scales, often only adult females were considered-for example, Ebeling (1947), with California red scale, Barnes and Stafford (1949), with fig scale, and Stafford (1954), with olive scale. When it is possible to work with some untreated trees, mortality (or per cent alive) in the treated plots may be adjusted for natural mortality, and the results may be expressed as "per cent control," "per cent reduction of live scales," etc.

Both mortality and number alive per a specified unit of host tree area have also been measured by a pre- and one or more post-treatment counts. The data in such experiments may be listed for each sampling date with no attempt to relate the two (Anthon, 1960). Often mathematical formulas have been employed to compare changes in scale populations receiving experimental treatments with changes in untreated populations or changes in populations under standard treatment. Working with San Jose scale, Snapp and Thomson (1943) used

$$
\frac{A X-Z}{A X} \times 100=\text { per cent control }
$$

in which $A$ is the ratio of the per cent alive in the untreated checks at the close of the experiment to the per cent alive at the beginning of the experiment; $X$ is the per cent alive in the sprayed plots before treatment; and $Z$ is the per cent alive in sprayed plots after treatment. Ebeling (1947) and Carman (1956), in their studies on control of California red scale, used a "corrected relative infestation" (CRI) based on the following equation:

$$
\frac{a b^{\prime}}{a^{\prime} b} \times 100=\mathrm{CRI}
$$

in which $a$ and $a^{\prime}$ are, respectively, pretreatment and post-treatment counts (live scale per selected unit of host surface) for a standard treatment, and $b$ and $b^{\prime}$ represent similar counts for any given treatment. Thompson (1962), in evaluating sprays for European elm scale control, used a method that may be represented as

$$
100-\frac{a b^{\prime} 100}{a^{\prime} b}=\text { per cent control }
$$

in which $a$ and $a^{\prime}$ are, respectively, pretreatment and post-treatment counts of live scales per branch unit for untreated trees, and $b$ and $b^{\prime}$ represent similar counts for any given treatment. The calculation represents the difference between calculated post-treatment count (based on the pretreatment count on treated trees, times the ratio of pre- to post-treatment counts on untreated trees) and the observed post-treatment count when this difference is expressed as a per cent of the calculated count. Negative figures on per cent control result when calculations are based on data from treated trees that show greater ratios of increase from pre- to posttreatment counts than do the untreated trees. Such cases have usually been listed in tables of results as zero per cent control. The equation used by

\footnotetext{
${ }^{2}$ See "Literature Cited" for citations referred to in the text by author and date.
} 
Snapp and Thomson (1943) can be put into the same form as the equation used by Thompson (1962) by having $a$ and $a^{\prime}$ represent, respectively, pre- and posttreatment per cent alive for untreated trees, and $b$ and $b^{\prime}$ represent similar values for the treated trees. The equations for CRI and per cent control given above show their similarity. The term, 100-CRI, would represent the per cent difference between a calculated posttreatment count based on a standard treatment, and the observed post-treatment count. If the standard treatment is more effective than the experimental treatment, the value for $100-C R I$ will be negative.

If data from tests are expressed as per cent reductions from pretreatment counts (or reductions from pretreatment per cent alive), and if no untreated check data are available,

$$
\frac{b-b^{\prime}}{b} \times 100=\text { per cent reduction }
$$

Negative percentages result with increases of infestations over pretreatment counts. The order of effectiveness of the treatments, however, will be the same as the order of treatments calculated by equations 1,2 , or 3 above. Where no pretreatment counts were made, the per cent reduction from an untreated check may be calculated as follows:

$$
\frac{a^{\prime}-b^{\prime}}{a^{\prime}} \times 100=\text { per cent reduction }
$$

Again, increases of infestation above that in the untreated check result in negative percentages.

\section{Collection of Control Data}

In the work reported here, four sampling methods were tried. Three were used to determine numbers of live or dead scales; the fourth accounted only for the progenies of survivors. The calendar period during which test sprays were applied and the time lapse between treatment and sampling determined whether the post-treatment samples con- tained only survivors and/or their progeny. Most of the earlier trials were assessed by one method only; in more recent trials, more than one sampling method was used. Each method provided a different criterion of population change.

Method I: Nonselective Counting. This conventional but laborious method involved the determination of numbers and condition of all of the scale insects on definable units of plant parts, such as whole twigs or fixed numbers of their basal internodes. The scale covers were lifted one by one in order to count the number of living scales in the total number examined. The tally for the total population included empty covers of metamorphosed males and all dead individuals of any kind. Only unaffixed crawlers were disregarded.

The twigs collected for nonselective counts were intentionally chosen for maximum infestation, and the counts included only insects on the parts of shoots that had developed during the season before the start of each experiment. The number of twigs taken from each of the trees was varied for different experiments according to number of scales on the twigs, size of trees, and number of trees in plots. Two variations of the method were tried. One involved pre- and post-treatment sampling. In the other, only post-treatment samples were taken, for comparison with samples from check plots.

Method II: Selective Counting. More than 100 short sections of heavily infested twigs and bark chips were collected as a composite sample by clipping approximately equivalent amounts of wood from each of the trees in one plot. These clippings were accumulated in a 1-quart fruit jar, and finally thoroughly mixed. The bits of wood were later examined individually as follows: $A l l$ of the scale covers within a small area on one bit of bark were lifted, but only two categories of scale insects were talliedthose found to be alive and those judged to have been spray-killed. Empty shells, 
parasitized scales, and mummified individuals were examined but not tallied. The counting was continued until the sum of the living and spray-killed individuals totaled 1,000 .

This method has several advantages. The tallies obtained for each sample may be recorded as a single value-the number of live individuals per 1,000 scales counted. Groups of such values are easily managed in statistical analyses. The examination of small areas on many bits of wood tends to minimize disturbance of the live/killed ratio when spray misses are encountered. However, these data do not reveal how the survivors are distributed on trees or within plots.

The check samples indicate only the proportions of dead scales that appear to have been spray-killed but which may have died from causes not related to applied toxicants.

Method III: Matched Strips. The matched-strip method compared numbers of live scales on a strip of untreated bark of fixed dimensions with numbers of survivors on a companion strip of bark removed at some chosen time after a spray was applied.

A sample unit consisted of a thin strip of bark, $1 / 4$ inch wide and 1 inch long, shaved from between two scored lines made with a double-bladed scoring tool.

A series of 5 to 25 strips were cut from one or more of the most heavily infested limbs of each tree in a plot. Strips scored for uniform width, and slightly longer than 1 inch, were collected from each tree and packaged in a small, waxed-paper sandwich bag. The strips were later cut to exactly 1 inch, and all of the living scales thereon were counted. The values for each tree were totaled and recorded. Each tree in a given plot was sampled a short time befor test sprays were applied.

A second set of strips was taken on a selected date after treatment and processed in like manner. The essential feature of the method is that each of the strips taken in the post-treatment sam- pling was cut as close as possible beside a scar that marked the place from which a first-sample strip had been cut. Thus each strip obtained in the second sampling matched closely one of those included in the pretreatment sample.

The procedure was found to be useful for sampling small segments of populations residing on heavy, smooth limbs. However, it had some disadvantages. The sampling had to be restricted to the plane surfaces of limbs large enough to tolerate two side-by-side cuts on their infested sectors. These are the limbs over which spray coverage is likely to be uniform and complete. The scoring tool tended to leave gaping wounds. The taking of a third or fourth set of homologous samples was not feasible because San Jose scales are usually not distributed uniformly around the circumfer. ences of heavy limbs.

Method IV: Annual Twigs. This procedure, reported by Stafford (1954) for olive scale, involved pre- and posttreatment counts of all of the scales (crawlers excepted) on whole twigs or on a fixed number of their basal internodes. The twigs were cut below their last annual growth rings and were selected from new growth arising from the main structural limbs of the tree. The pretreatment samples of twigs were taken during the dormant period immediately preceding the season in which the sprays were to be applied. The posttreatment samples were taken from the same trees during the next dormant period, approximately one year after the first sampling. In both cases, all of the scales on the wood produced in the preceding growing season were counted, regardless of sex, growth stage, or whether the scales were dead or alive. Post-treatment counts represented an accumulation on new wood of the progeny of treatment survivors.

During development of the annualtwig method for use with San Jose scale, the pretreatment counts were used in various ways as the basis for assigning trees to the proposed treatments. After 
1959 (with one exception) this method was used with single-tree plots in the following manner. The host trees were inspected for acceptable levels of infestation, and those selected were tagged and coded. Sample twigs were then cut, and the scales on the last season's growth were counted. The sums of scale counts for each tree (together with corresponding tree locations) were listed in descending order of value. The list was marked off at equal intervals into class groups-as many groups as trees per treatment. Beginning at the top of the column, a different treatment was assigned to each tree, in order, until each proposed treatment had been listed. As a result, each treatment was assigned to a tree in the highest range of initial infestation (first group). Con- tinuing down the column, each treatment was again assigned to a single tree in the next group, but with the order of treatments reversed. The process was continued, reversing the order of treatments for each succeeding group. This procedure tended to make the averages of initial numbers of scales per tree more nearly uniform among the treatments than would be the case if trees were sorted by visual inspection only, without regard to groups.

The annual-twig method provides a useful estimate of population survival and recovery, with treatment and environmental effects lumped. It loses its serviceability if spray operations are delayed too long after first-generation crawlers settle and develop on new wood in the spring.

\section{TIMING OF SPRAYS AND PERIODS APPROPRIATE FOR SAMPLING}

All of the results reported here pertain to sprays that were applied manually. In all cases, enough spray was used to ensure thorough coverage.

\section{Fall and Winter Sprays}

In the interior valleys of California, the relative numbers of each of the immature stages in wintering populations of San Jose scale change during late winter because the mild climate permits the insects to develop slowly (Gentile and Summers, 1958). The effectiveness of sprays should therefore be expected to vary somewhat according to date of application.

Several of the experiments set up to demonstrate possible differences between sprays applied at various times during fall and winter were also useful for exploring the question of how much time must elapse between spraying and sampling in order to secure significant performance data.

One of the first experiments with late fall oil-organophosphorus sprays was designed to compare the response of a severe infestation in plums in one part of the state with a comparably treated orchard elsewhere (table 1). The plums were suspected of having a parathionresistant strain of San Jose scale, because prior winter sprays appeared only to palliate but not control the pest. A severely infested prune orchard located elsewhere was selected for comparison because it had not been previously treated with organophosphorus insecticides. The test sprays were applied in both orchards during October, 1956, and nonselective scale counts on twigs were made in December. According to the criteria used, the two infestations were similarly affected; the sprays reduced the infestations by approximately 99 per cent within 65 to 70 days after treatment. However, the infestation in the prune orchard increased rapidly during the next growing season, and the duration of control was unsatisfactory. The plum orchard was pulled out soon after the last samples were taken.

The effect of fall sprays was further tested in several trials completed during 


\section{TABLE 1}

SIMILARLY SPRAYED TREES IN TWO ORCHARDS COMPARED BY NONSELECTIVE COUNTS OF SCALES ON ONE-YEAR TWIGS

(Gridley and Woodlake, California, 1956)

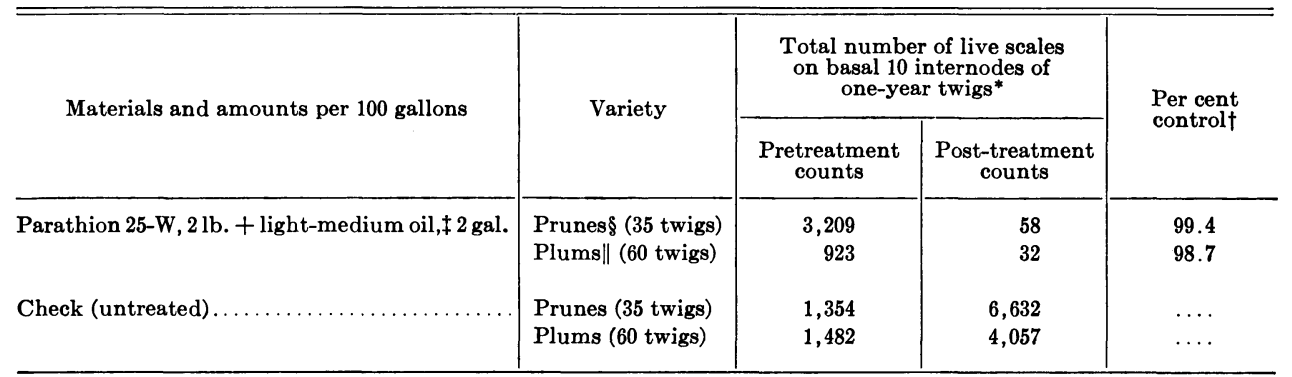

* Method I, nonselective counting (see p. 15).

t See Equation (3), p. 14

$\ddagger$ Niagara Summer Flowable Emulsion for prunes; Orthol-K Light-Medium Flowable, for plums.

Imperial prunes, Gridley, sprayed October 9; pretreatment samples collected October 9, post-treatment samples collected December $13 ; 5$ trees per plot, 7 twigs per tree.

I| Santa Rosa plums, Woodlake, sprayed October 10; pretreatment samples collected October 4, post-treatment samples collected December 19; 6 trees per plot, 10 twigs per tree.

1957-1958. A series of oil and oilorganophosphorus sprays was applied to prune trees on October 8, and evaluated by selective scale counts 37 days later, on November 14 (table 2). The numbers of survivors so greatly exceeded expectation that three of the treated plots were resampled on Decem- ber 9 , or 72 days after treatment. The later sampling did not show increased numbers of dead scales. Another series of test sprays on infested peach trees on November 19, 1957, coincided with the date on which fungicides were normally applied to control leaf curl. The organophosphorus insecticides were tank-mixed

TABLE 2

\section{APPRAISAL BY SELECTIVE SCALE COUNTS OF POSTHARVEST SPRAYS APPLIED TO FRENCH PRUNES*}

(Gridley, California, 1957)

\begin{tabular}{|c|c|c|c|c|c|}
\hline \multirow{4}{*}{ Materials and amounts per 100 gallons } & \multicolumn{3}{|c|}{ Number of live scales per $1,000 \dagger$} & \multicolumn{2}{|c|}{ Per cent reduction $\ddagger$} \\
\hline & \multicolumn{3}{|c|}{ Days after spraying } & \multicolumn{2}{|c|}{ Days after treatment } \\
\hline & \multicolumn{2}{|c|}{37} & \multirow{2}{*}{72} & \multirow{2}{*}{37} & \multirow{2}{*}{72} \\
\hline & Rep. A & Rep. B & & & \\
\hline Volck Supreme oil, 1.6 gal................ & 763 & 772 & $\ldots$ & 18.0 & . \\
\hline 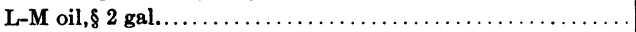 & 770 & 794 & $\ldots$ & 16.4 & $\ldots$ \\
\hline Malathion 8-EC,\| 1/2 pt. + L-M oil, 2 gal..... & 781 & 768 & $\ldots$ & 17.2 & $\ldots$ \\
\hline Dylox 50-W, 1/2 lb. + L-M oil, 2 gal............ & 728 & 705 & $\ldots$ & 22.3 & . \\
\hline Naled 8-EC $\| 1 / 2$ pt. + Volck Supreme oil, 1.5 gal.... & 738 & 756 & $\ldots$ & 20.1 & $\ldots$ \\
\hline Diazinon 25-W, 1 lb. + Volck Supreme oil, 1.5 gal.. & 335 & 384 & .. & 61.6 & $\ldots$ \\
\hline Ethion 4-EC, $1 / 2$ pt. + L-M oil, 2 gal........... & 797 & 760 & 783 & 16.8 & 16.4 \\
\hline Carbophenothion 4-EK, $1 / 2$ pt. + L-M oil, 2 gal. ..... & 606 & 679 & $\ldots$ & 31.3 & $\ldots$ \\
\hline Parathion 4-EC, 1/2 pt. + L-M oil, 2 gal......... & 255 & 299 & 342 & 70.4 & 63.5 \\
\hline Parathion 25-W, 2 lb. + L-M oil, 2 gal... & 197 & 150 & 180 & 81.5 & 80.8 \\
\hline Check (untreated).$\ldots \ldots \ldots \ldots \ldots \ldots$ & 948 & 923 & 937 & $\ldots$ & $\ldots$ \\
\hline
\end{tabular}

* Sprayed October 18. Composite samples of twig sections and bark chips collected from 4 trees per plot (2 replications) on November 14. Sampling repeated in 4 plots on December 19. Replications averaged for first sampling date for use with Equation (5)

† Method II, selective counting (see p. 15).

See Equation (5) p. 15.

Orthol-K Light-Medium Flowable Emulsion, N. W.

if Emulsifiable concentrates formulated especially for use in oil sprays. 
TABLE 3

RESULTS OBTAINED WITH EXPERIMENTAL SPRAYS TO CONTROL SAN JOSE SCALE ON ELBERTA PEACHES* DURING THE LATE FALL (Parlier, California, 1957-1958)

\begin{tabular}{|c|c|c|c|c|}
\hline \multirow{2}{*}{ Materials and amounts per 100 gallons $\dagger$} & \multicolumn{2}{|c|}{ Dormant oil emulsion $\ddagger$} & \multicolumn{2}{|c|}{ Volck Supreme oil§ } \\
\hline & $\begin{array}{l}\text { Live scales } \\
\text { per } 1,000 \|\end{array}$ & $\begin{array}{l}\text { Per cent } \\
\text { reduction } \mathbb{I}\end{array}$ & $\begin{array}{l}\text { Live scales } \\
\text { per } 1,000 \|\end{array}$ & $\begin{array}{l}\text { Per cent } \\
\text { reduction } 9\end{array}$ \\
\hline Parathion 4-EC, $1 / 2$ pt.... & 126 & 86.3 & 168 & 81.6 \\
\hline Parathion 25-W, 2 lb.... & 57 & 93.8 & 134 & 85.3 \\
\hline Malathion $8-\mathrm{EC}, 1 / 2 \mathrm{pt} . . .$. & 145 & 84.3 & 109 & 88.1 \\
\hline Naled $8-E C, 1 / 2$ pt........ & 213 & 76.9 & 112 & 87.7 \\
\hline Diazinon 2-EC, 1 pt....... & 141 & 84.7 & 185 & 79.7 \\
\hline Carbophenothion 4-EK, 1/2 pt. . & 245 & 73.4 & 265 & 71.0 \\
\hline Ethion 4 -EC, $1 / 2$ pt.......... & 164 & 82.2 & 67 & 92.7 \\
\hline 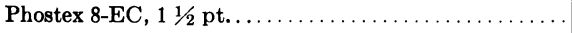 & 70 & 92.4 & 94 & 89.7 \\
\hline 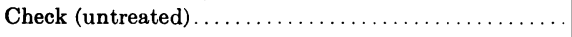 & 921 & $\ldots$ & 913 & $\cdots$ \\
\hline
\end{tabular}

* Six trees per plot, sprayed November 19, 1957. Selective scale counts made for one composite sample per plot; samples collected January 8,1958

† Copper oxychloride sulphate, $4 \mathrm{lb}$. per $100 \mathrm{gal}$. included in each spray.

¥ Used at the rate of 1.5 gal. per 100 gal. water.

Used at the rate of 1.2 gal. per 100 gal. water.

Method II, selective counting (see p. 15)

I See Equation (5), p. 15.

with two kinds of oil (table 3 ). Another group of plots in the same orchard was sprayed with several oil-organophosphorus mixtures on January 21, 1958 (table 4 ). The amounts of oil were increased in these full dormant sprays. Both series of peach plots were appraised by selective scale counts approximately 50 days after treatment. The spray mixtures thought to be appropriate for fall application, in November, did not perform favorably when compared with the midwinter sprays.

In order to reexamine the hypothesis that late winter sprays give better results than late fall or early winter sprays, extremely infested French prunes were sprayed on a succession of

TABLE 4

RESULTS OBTAINED WITH FULL DORMANT SPRAYS APPLIED TO ELBERTA PEACHES*

(Parlier, California, 1958)

\begin{tabular}{|c|c|c|}
\hline Materials and amounts per 100 gallons & $\begin{array}{c}\text { Number of } \\
\text { live scales in } \\
1,000 \text { counted } \dagger\end{array}$ & $\begin{array}{l}\text { Per cent } \\
\text { reduction } \ddagger\end{array}$ \\
\hline \multicolumn{3}{|l|}{ Orchard A: } \\
\hline Diazinon 25-W, 2 lb. + DOE, $\$ 3$ gal. . & 7 & 99.2 \\
\hline Parathion 25-W, 2 lb. + DOE, 3 gal... & 7 & 99.2 \\
\hline Check (untreated) $\ldots \ldots \ldots \ldots \ldots \ldots \ldots \ldots$ & 913 & $\cdots$ \\
\hline \multicolumn{3}{|l|}{ Orchard B: } \\
\hline Ethion 4-EC, 1/2 pt. + DOE, 2 gal.. & 11 & 98.8 \\
\hline Ethion 4-EC, 1/2 pt. + DOE, 3 gal... & 7 & 99.2 \\
\hline 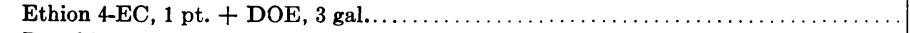 & 3 & 99.7 \\
\hline Parathion 25-W, 2 lb. + DOE, 3 gal............ & 0 & 100.0 \\
\hline Carbophenothion 4-EK, $1 / 2$ pt. + DOE, 2 gal... & 17 & 98.1 \\
\hline Carbophenothion 4-EK, $1 / 2$ pt. + DOE, 3 gal.. & 2 & 99.8 \\
\hline Phostex 8-EC, 1 pt. + DOE, 3 gal.......... & 3 & 99.7 \\
\hline Check (untreated) $\ldots \ldots \ldots \ldots \ldots \ldots \ldots$ & 885 & $\ldots$ \\
\hline
\end{tabular}

* Six trees per plot, sprayed January 21, 1958. Selective scale counts for one composite sample per plot taken March 13. † Method II, selective counting (see p. 15).

† See Equation (5), p. 15.

$\$ \mathrm{DOE}=$ Ortho Kleenup Flowable dormant oil emulsion. 
TABLE 5

SELECTIVE SCALE COUNTS OBTAINED AFTER SPRAYING FRENCH PRUNES TO CONTROL SAN JOSE SCALE

(Princeton, California, 1958-1959)

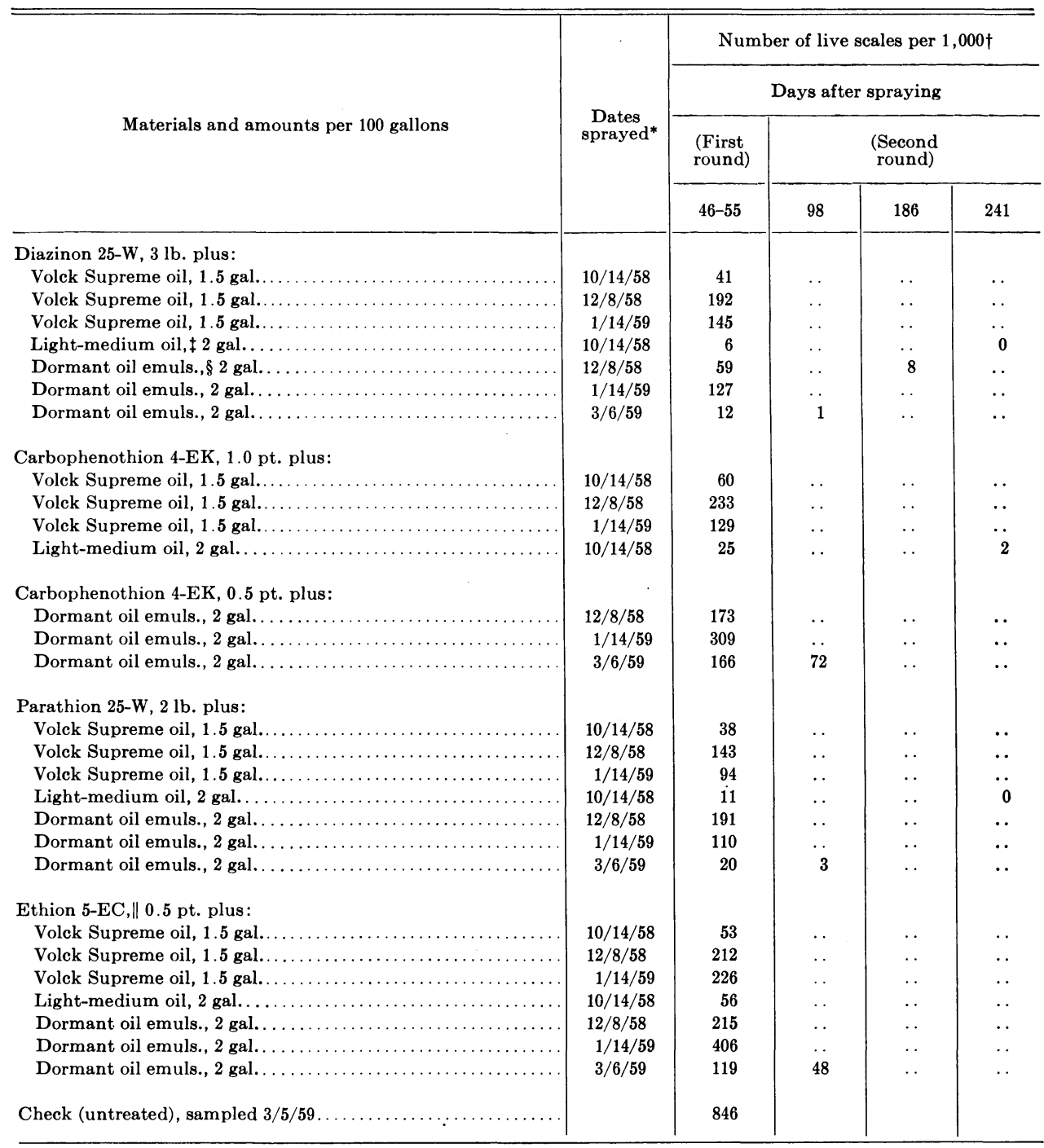

* Four or five one-tree replications per treatment. Preliminary counts of number of scale-infested prunes per 100 used to sort trees into treatments. First round of samples: trees sprayed on $10 / 14 / 58$ sampled 12/9/58; on 12/8/58, sampled $1 / 27 / 59$; on $1 / 14 / 59$, sampled $3 / 10 / 59$; on $3 / 6 / 59$, sampled $4 / 21 / 59$. Second round of samples from holdover treatments taken on $6 / 12 / 59$.

\footnotetext{
$\dagger$ Method II, selective counting (see p. 15).
† Orthol-K Light-Medium Flowable.

Ortho Kleenup Flowable.

|f Experimental formulation CR-2911.
} 
dates: October 14 and December 8, 1958, and January 14, 1959 (table 5). The intention was to apply identical amounts of each organophosphorus chemical in 1.5 gallons of Volck Supreme oil on the successive dates. A parallel series was set up to test the same insecticides with 2 gallons of conventional flowable oil emulsion, but with grades of oil adjusted to fit the period. The time sequence was later extended to include pre-pink sprays (March 6), and the dosage of one insecticide, carbophenothion, was varied. Only one check plot was permissible because the scale attack was critical; this plot was sampled once and then sprayed in the final round of tests. The test plots were sprayed and evaluated in turn, each one about seven to eight weeks after treatment, by the selective-count method.

The data obtained from the prune plots sprayed on successive dates are difficult to interpret. With respect to treatment periods, the October sprays apparently gave better results than late fall or early winter sprays. Although results of the sprays containing parathion and Diazinon could possibly be distinguished from results with the other sprays, all appeared to leave excessive numbers of survivors. Thus, the erratic performance data again introduced the question about reliability of sampling procedures involved in evaluating treatments. The fixing of the sampling date was suspected as a major source of confusion.

When the selective counting method was adopted, the elapsed time between dates of spraying and of sampling for performance data was roughly fixed by inspecting several pilot samples to $\mathrm{d} \varepsilon$ termine when affected scales darkened in color and dried sufficiently to be recognizable as "spray-killed." When pilot samples indicated that live and dead scales could be separated readily, definitive sampling was carried out. A small percentage of individuals always had to be classified arbitrarily. Prematurely drawn samples could not be processed.
The interim pilot samplings showed that longer intervals - five to eight weeks-between the dates of spraying and final sampling apparently were required when oils were used or during periods of low temperatures and high humidity. Warm, dry weather shortened the waiting period.

Limited extension of the waiting period did not, at first, appear to affect the counts (table 2, 72 days). However, in one of the experiments on prunes (table 5), dissatisfaction with the performance data led to a recheck on the sampling time. Only eight of the original 28 plots could be held over for subsequent study; all others were sprayed again. Samples were taken from the holdover plots during June. This second round of samples showed fewer live scales than did the first.

The possibility that short-term or once-over evaluations do not in any case adequately assess treatment effects on San Jose scale was considered in another experiment (table 6). Three methods were used to assess plots of wintersprayed peaches, each to reveal a different aspect of control and to serve as a check on the others. Twin strip samples and bark chips for selective counts were taken on May 10. It was planned to repeat these selective counts at monthly intervals until maximum population reduction became evident. The two types of samples taken on this first date yielded similar values, and the numbers of survivors were so small that repetition to show further downward change in the surviving population was considered pointless. The post-treatment evaluation by the annual-twig method was relied upon to reveal the status of the infestation at the end of the growing season.

Examination of the population during May by methods II and III (table 6) showed only 0.1 to 1.9 per cent alive (II), and reductions of live scales from the December pretreatment counts (III) greater than 99 per cent. Excellent control could be inferred from either of 
TABLE 6

EVALUATION OF FOUR DORMANT TREATMENTS ON PEACH TREES BY THREE SAMPLING METHODS*

(Fowler, California, 1960)

\begin{tabular}{|c|c|c|c|c|c|c|c|}
\hline \multirow{2}{*}{$\begin{array}{l}\text { Materials and amounts } \\
\text { per } 100 \text { gallons } \dagger\end{array}$} & \multirow{2}{*}{$\begin{array}{c}\text { Method II } \\
\text { Total } \\
\text { live } \\
\text { scales } \\
\text { per } 1,000 \\
\text { counted } \\
5 / 10 / 60\end{array}$} & \multicolumn{3}{|c|}{ Method III } & \multicolumn{3}{|c|}{ Method IV } \\
\hline & & $12 / 16 / 59$ & $5 / 10 / 60$ & $\begin{array}{l}\text { Per cent } \\
\text { reduction } \ddagger\end{array}$ & $12 / 16 / 59$ & $11 / 15 / 60$ & $\begin{array}{l}\text { Per cent } \\
\text { reduction } \ddagger\end{array}$ \\
\hline Volck Supreme oil, 2.5 gal... & 58 & 13,190 & 15 & 99.9 & 30,854 & 34,790 & -12.8 \\
\hline Kleenup Flowable oil, 3 gal. . & 33 & 11,732 & 28 & 99.8 & 31,764 & 43,265 & -36.2 \\
\hline \multirow[t]{2}{*}{$\begin{array}{l}\text { Carbophenothion-oil }(0.16 \\
\text { lb./gal.), } 2.5 \text { gal.......... }\end{array}$} & $\begin{array}{l}2 \\
2 \\
3\end{array}$ & $\begin{array}{l}3,187 \\
3,918 \\
1,594\end{array}$ & $\begin{array}{l}2 \\
7 \\
4\end{array}$ & & $\begin{array}{r}11,986 \\
8,092 \\
11,649\end{array}$ & $\begin{array}{r}12,030 \\
9,840 \\
10,195\end{array}$ & \\
\hline & 7 & 8,699 & 13 & 99.9 & 31,727 & 32,065 & -1.1 \\
\hline $\begin{array}{l}\text { Ethion-oil (0.16 lb./gal. in } \\
\text { Volck Supreme oil), } 2.5 \text { gal. }\end{array}$ & $\begin{array}{l}0 \\
1 \\
2\end{array}$ & $\begin{array}{l}5,528 \\
4,241 \\
3,826\end{array}$ & $\begin{array}{l}0 \\
0 \\
2\end{array}$ & & $\begin{array}{r}12,045 \\
13,439 \\
9,409\end{array}$ & $\begin{array}{l}8,035 \\
7,550 \\
7,525\end{array}$ & \\
\hline
\end{tabular}

* Trees sprayed $2 / 11 / 60$. Five trees per plot, originally sorted into plot groups according to pretreatment counts on matched strips. One composite sample per plot to selective counts of scales on bark chips and twig sections. Matched

strips, 5 per tree; annual twigs, 10 per tree. For description of the methods, see text.
+ Experimental formulations of carbophenothion in Niagara dormant emulsion oil and Ethion in Volck Supreme emulsive oil supplied by Niagara Chemical Company, Richmond, California.

$\ddagger$ See Equation (4), p. 15.

these criteria. On the other hand, data from the annual-twig method (IV) indicated poor control. The latter information alone could have led to the erroneous conclusion that the population had not been greatly reduced during the period from December to May.

The question of when to spray during fall or winter for best results with particular sprays could not be clearly resolved until a satisfactory routine was established for evaluating treatment effects. It now appears that the sampling procedures should be extended in time to show population trends after treatment.

\section{Spring Sprays}

As early as 1953, mid-May appeared promising as a time for spraying to con- trol San Jose scale although the data obtained from the sprays were inadequate for distinguishing between treatments (table 7). Mid-May was chosen as a strategic period for spraying because first-generation crawlers of San Jose scale begin to appear in good numbers at that time, and because some materials applied then for San Jose scale also control the peach twig borer (Anarsia lineatella Zell.). O'Neill (1951) also concluded that the best time to spray for control of San Jose scale in Washington was in June just before the crawlers appeared.

Follow-up trials were set up for several seasons, but the results were erratic. Favorable results following routine experiments with May sprays applied during 1958 and 1959 (table 8), however, 
TABLE 7

NONSELECTIVE SCALE COUNTS FOR TWIG SAMPLES* FROM PEACH TREES RECEIVING DORMANT OR SPRING SPRAYS TO CONTROL SAN JOSE SCALE

(Hughson, California, 1952-1953)

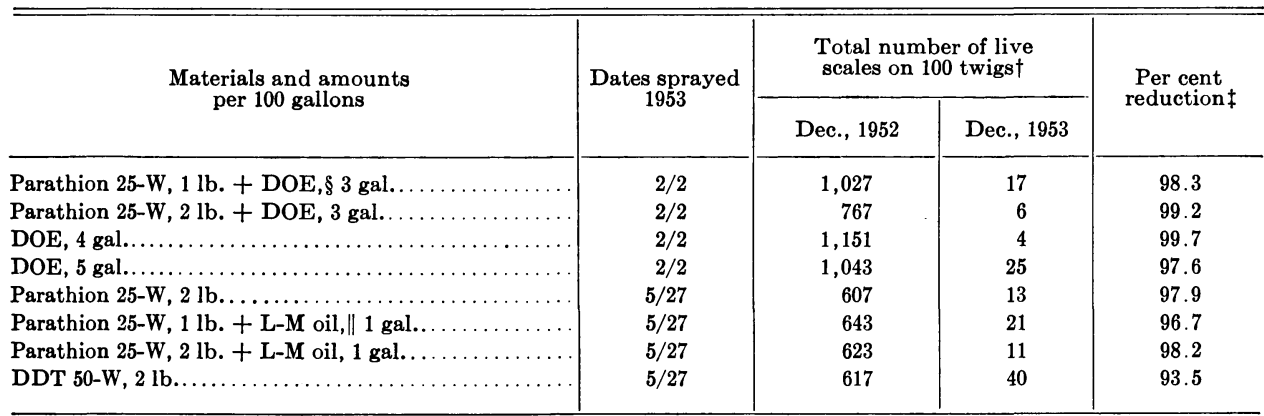

* Samples comprised 20 twigs per tree, 5 trees per treatment. Scales counted on basal 15 nodes of each twig.

$\dagger$ Method I, nonselective counting (see p. 15).

† See Equation (4), p. 15.

$\$$ Ortho Kleenup dormant oil emulsion.

U L-M oil = Niagara Light-Medium Flowable oil emulsion.

encouraged the writers to attempt a more comprehensive experiment during 1961. The essential details of that operation are summarized in table 9 .

The experiment was organized 1) to determine the time interval between treatment dates and maximum discernible effect as demonstrated by selective scale counts repeated at three intervals; 2 ) to see whether variations of \pm 10 days in date of application of one spray (carbophenothion) could be detected by this sampling procedure (table 10); 3) to compare the data so obtained with data on postseason recovery of the infesta- tion; and 4) to get data useful for comparing end-of-season recovery following spring sprays with similar data obtained in other experiments on winter sprays (tables 11 and 6 ). Only one winter spray (table 9, J) was included in this series.

Selective scale counts were first made 42 days after the target date for putting on the spring sprays (May 19). On the first sampling date (June 30) the numbers of survivors were very small in all of the spring-sprayed plots. Since these samples were not replicated, the selective counts obtained on the successive

TABLE 8

RESULTS WITH SPRING SPRAYS* APPLIED TO PEACH TREES, TO CONTROL SAN JOSE SCALE

(Fresno, California, 1959)

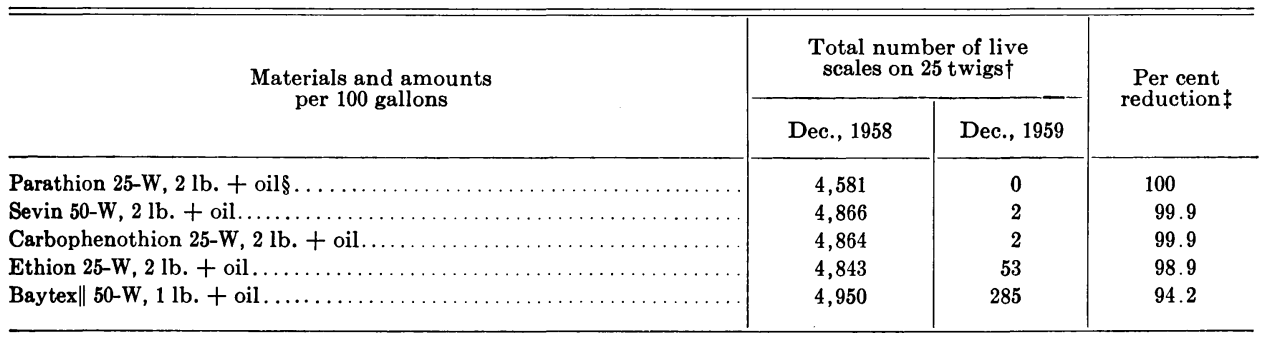

* Trees sprayed 5/13/59.

† Samples comprised 5 twigs per tree, 5 trees per treatment. Scales counted on basal 10 nodes of each twig. Method IV, annual twigs (see p. 16).

$\ddagger$ See Equation (4), p. 15 .

Niagara Light-Medium Flowable emulsion, 1 gal. per 100 gal.

Bayer $29493=0,0$-Dimethyl O-[4-(Methylthio)-m-tolyl] phosphorothioate. 
TABLE 9

TWO-WAY APPRAISAL OF MAY SPRAYS APPLIED TO PEACH TREES*

(Fowler, California, 1961)

\begin{tabular}{|c|c|c|c|c|c|c|c|c|}
\hline \multirow{2}{*}{$\begin{array}{l}\text { Materials and amounts } \\
\text { per } 100 \text { gallons } \dagger\end{array}$} & \multirow{2}{*}{ Plot } & \multirow{2}{*}{$\begin{array}{l}\text { Dates } \\
\text { sprayed } \\
1961\end{array}$} & \multicolumn{3}{|c|}{$\begin{array}{c}\text { Selective scale counts, } \ddagger \\
1961 \text {, total live scales } \\
\text { per } 1,000\end{array}$} & \multicolumn{2}{|c|}{$\begin{array}{c}\text { Annual-twig method, } \\
\text { total live scales } \\
\text { on } 30 \text { twigs } 8\end{array}$} & \multirow{2}{*}{$\begin{array}{l}\text { Per cent } \\
\text { reduc- } \\
\text { tion" }\end{array}$} \\
\hline & & & $6 / 30$ & $8 / 8$ & $9 / 5$ & $11 / 60$ & $11 / 619$ & \\
\hline Guthion $25-\mathrm{W}, 2 \mathrm{lb} .$. & $\mathbf{A}$ & $5 / 22$ & 6 & 1 & 0 & 9,824 & $26 \mathrm{a}$ & 99.7 \\
\hline Carbophenothion 25-W, 2 lb.. & $\mathrm{B}$ & $5 / 19$ & 4 & 2 & 29 & 11,309 & $129 \mathrm{ab}$ & 98.9 \\
\hline Parathion 25-W, 2 lb........ & $\mathrm{C}$ & $5 / 19$ & 0 & 0 & 2 & 11,205 & $253 \mathrm{ab}$ & 97.7 \\
\hline Carbophenothion $25-\mathrm{W}, 2 \mathrm{lb}$. & D & $5 / 10$ & 3 & 1 & 55 & 10,593 & $343 \mathrm{ab}$ & 96.8 \\
\hline Sevin $50-W, 2$ lb......... & $\mathrm{E}$ & $5 / 19$ & 6 & 0 & 0 & 10,997 & $363 \mathrm{ab}$ & 96.7 \\
\hline Ethion $25-\mathrm{W}, 2 \mathrm{lb} . .$. & $\mathrm{F}$ & $5 / 19$ & 31 & 15 & 33 & 11,251 & $495 \mathrm{ab}$ & 95.6 \\
\hline Diaz-N-Oil, ${ }^{* *} 1$ gal... & $\mathrm{G}$ & $5 / 19$ & 0 & 0 & 30 & 11,644 & $695 \mathrm{ab}$ & 94.0 \\
\hline Carbophenothion 25-W, $2 \mathrm{lb}$. . & $\mathbf{H}$ & $5 / 29$ & 12 & 10 & 57 & 9,646 & $767 \mathrm{~b}$ & 91.9 \\
\hline Naled 8 -EC, 0.5 pt.......... & I & $5 / 19$ & 6 & 34 & 112 & 10,979 & $1,533 \mathrm{c}$ & 86.0 \\
\hline Carbophenothion in oil, $\dagger \dagger 2.5$ gal....... & $\mathbf{J}$ & $2 / 10$ & 297 & 323 & 222 & 9,565 & 3,887 & 59.4 \\
\hline
\end{tabular}

* Six trees per treatment, grouped according to pretreatment counts of scales on twigs.

$\dagger$ All treatments except for plot G contained 1 gal. of light-medium oil emulsion per 100 gal.

† One composite sample of bark chips and twig sections taken from 6 trees on each date.

$\$$ Pre- and post-treatment counts based on 5 twigs per tree.

See Equation (4). p. 15 .

May sprays not sharing the same letters are significantly different at $5 \%$ by Duncan's multiple-range test. Per cent reduction given only for counts of scales on annual twigs.

** Light-medium emulsifiable oil containing $0.5 \mathrm{lb}$. Diazinon per gal., supplied by Moyer Chemical Company, San Jose, California.

†† Volck Supreme emulsifiable oil containing $0.16 \mathrm{lb}$. carbophenothion per gal., supplied by Niagara Chemical Company, Richmond, California.

sampling dates were regarded as significant only as they revealed definite trends. The sequence of selective counts for plots A, C, and E (table 9) showed no obvious change. Post-treatment increase of the infestation seemed to be clearly identifiable in the counts from plot I, and possibly identifiable in the case of plots B, D, and $H$. The effect of variations in timing of the carbophenothion sprays was not discernible.
Sprays applied to prunes at Yuba City during May, 1961, showed fair to good control by annual-twig counts (table 10). The data indicated that, in this region, sprays applied in late May may be more effective than sprays applied earlier in that month.

A larger series of samples seemed to be required to demonstrate when the maximum depression point occurred in plots treated with different scalecides.

TABLE 10

VARIATIONS IN TIMING OF A MAY SPRAY ON FRENCH PRUNES EVALUATED BY COUNTS OF LIVE SCALES ON ANNUAL TWIGS

(Yuba City, California, 1961)

\begin{tabular}{|c|c|c|c|}
\hline \multirow{2}{*}{ Dates sprayed* } & \multicolumn{2}{|c|}{$\begin{array}{c}\text { Total number of scales } \\
\text { on } 50 \text { twigs } \dagger\end{array}$} & \multirow{2}{*}{$\begin{array}{l}\text { Per cent } \\
\text { reduction }\end{array}$} \\
\hline & $2 / 10 / 61$ & $11 / 27 / 61$ & \\
\hline May $5 \ldots \ldots$ & 3,141 & 609 & 80.6 \\
\hline May $23 \ldots .$. & 3,082 & 454 & 85.3 \\
\hline May 29 & 3,325 & 190 & 94.3 \\
\hline
\end{tabular}

* Trees sprayed each time with carbophenothion 25-W, 2 lb., and light-medium summer oil emulsion, 1 gal. per 100 gal. water. Trees sorted into treatment groups by pretreatment counts, 5 trees per treatment.

$\dagger$ Live scales counted on entire twigs, 10 twigs per tree. Method IV, annual twigs (see p. 16).

† See Equation (4), p. 15. 
TABLe 11

COUNTS OF SCALES ON ANNUAL TWIGS FROM PEACH TREES* SPRAYED WITH A SERIES OF OIL-INSECTICIDE MIXTURES

(Fowler, California, 1959-1960)

\begin{tabular}{|c|c|c|c|}
\hline \multirow{2}{*}{$\begin{array}{l}\text { Materials and amounts } \\
\text { per } 100 \text { gallons }\end{array}$} & \multicolumn{2}{|c|}{$\begin{array}{l}\text { Total number of live } \\
\text { scales on } 30 \text { twigs } \dagger\end{array}$} & \multirow{2}{*}{$\begin{array}{l}\text { Per cent } \\
\text { reduction } \ddagger\end{array}$} \\
\hline & $12 / 15 / 59$ & $11 / 15 / 60 \S$ & \\
\hline 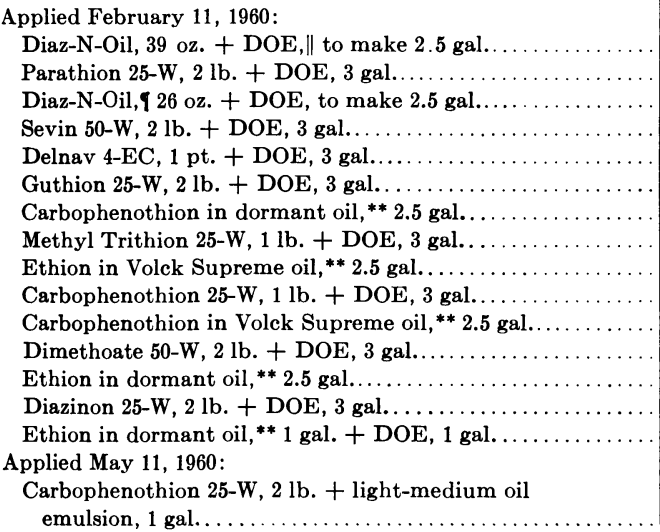 & $\begin{array}{l}17,284 \\
23,927 \\
17,159 \\
15,132 \\
15,135 \\
15,835 \\
17,785 \\
15,348 \\
14,562 \\
18,336 \\
14,960 \\
15,978 \\
17,516 \\
17,692 \\
16,123 \\
\\
15,550\end{array}$ & $\begin{array}{c}6,109 \mathrm{a} \\
7,777 \mathrm{ab} \\
7,919 \mathrm{ab} \\
8,161 \mathrm{ab} \\
8,857 \mathrm{ab} \\
10,002 \mathrm{ab} \\
10,141 \mathrm{ab} \\
10,289 \mathrm{ab} \\
10,302 \mathrm{ab} \\
10,896 \mathrm{ab} \\
11,032 \mathrm{ab} \\
13,607 \mathrm{ab} \\
15,070 \mathrm{ab} \\
16,417 \mathrm{bc} \\
23,719 \mathrm{c} \\
\end{array}$ & $\begin{array}{r}64.7 \\
67.5 \\
53.8 \\
46.1 \\
41.5 \\
36.8 \\
48.7 \\
33.0 \\
29.2 \\
40.6 \\
26.3 \\
14.8 \\
14.0 \\
6.7 \\
-47.8\end{array}$ \\
\hline
\end{tabular}

* Six trees per treatment. Trees sorted to treatment groups as described in text.

$\dagger$ Scales counted on 10 basal internodes of 5 twigs per tree. Method IV, annual twigs (see p. 16).

See Equation (4), p. 15 . test.

$\$$ Post-treatment counts not sharing the same letters are significantly different at $5 \%$ by Duncan's multiple-range

II DOE $=$ dormant oil emulsion.

Diaz-N-Oil = dormant emulsive oil containing $2 \mathrm{lb}$. Diazinon per gal., supplied by Moyer Chemical Company, San Jose, California.

oil, supplied by Niagara Chemical Company.

The selective counts shown in table 9 indicated that the dates at which maximum effect of treatment on population appeared were not concurrent for the several test sprays. For parathion, Diaz$\mathrm{N}$-oil, and naled the greatest effect was evident on the first sampling date, or 42 days after treatment. The peak effect for the other materials applied during May probably occurred during the period in which selective counts were made.

Appraisal of the same plots by the annual-twig method showed that the infestation did not regenerate appreciably in most of the plots before the onset of winter. The trend of scale recovery on the trees sprayed with naled (table $9, I$ ), as shown by the sequence of selective counts, was identifiable in the end-ofseason appraisal; otherwise there was no obvious correlation between the num- bers of live scales per 1,000 counted during summer and the numbers of scales on twigs examined during November. The plots in which various sprays were applied in May had lighter infestations during November than did the single plot sprayed in February (table 9, $\mathbf{J}$ ). None of the dormant sprays applied in the same peach orchard in February, 1960, prevented serious reinfestation of twigs before the end of summer, 1960 (tables 11 and 6).

That May sprays gave better results than dormant sprays was more clearly demonstrated when both were compared in the same orchard. Probably spring sprays were more effective because the physical environment and stage in the life cycle of the pest were more favorable for chemical control. The temperature is higher and the metabolism of the reproducing and growing scales is 
TABLE 12

LIVE SCALES ON MATCHED-STRIP SAMPLES FROM IMPERIAL PRUNE TREES SPRAYED* IN EARLY WINTER TO COMPARE TWO SPRAYS (Gridley, California, 1955-1956)

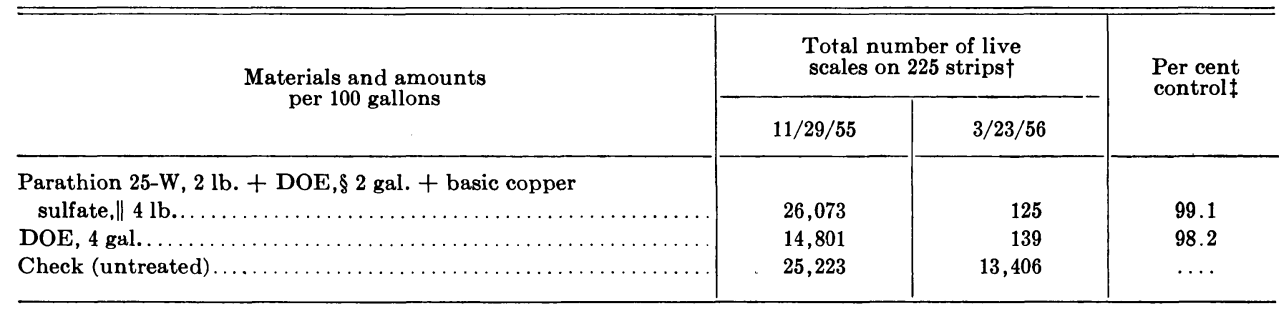

* Trees sprayed December 12, 1955, 9 trees per treatment, sorted into treatment groups by visual inspection. $\dagger$ Sample strips, 25 per tree (6.25 sq. in.) on each date. Method III, matched strips (see p. 16). See Equation (3), p. 14 .

DOE = Ortho Kleenup dormant oil emulsion.

$\|$ Added to one spray to test scalecidal effect of the combination possibly useful for peach trees.

greater in spring than in the dormant period. Moreover, the progeny of the survivors-crawlers especially - are subjected to persistent spray residues. Successful establishment of crawlers may be prevented during a part of the first reproductive period except on small areas of the trees that are inadequately covered with spray. The result may be a shortening of the period during which reproduction can take place. In contrast, the residual effects of winter sprays dissipate before reproduction begins in May.

\section{SPRAY MATERIALS}

Although comparison of spray treatments is not a primary objective of this paper, the data presented (together with unpublished data) support some general conclusions. Winter sprays containing as much as 4 gallons of oil emulsion per 100 gallons of water were as effective in controlling San Jose scale as any of the oil-organophosphorus mixtures tried (tables 7 and 12). Of all of the organophosphorus insecticides used with oil in winter sprays, parathion has been most consistently effective (tables
$3,4,5$, and 11). However, it was not possible to show conclusively any differences among Delnav, diazinon, dimethoate, ethion, Guthion, methyl Trithion, parathion, Phostex, Sevin, or carbophenothion when they were used with oil in dormant sprays (tables 4 and 11). Neither was it possible to show conclusively any differences among diazinon, ethion, Guthion, parathion, Sevin, or carbophenothion when they were used with oil in spring sprays (tables 8 and 9 ).

\section{POPULATION RESURGENCE}

Some infestations of San Jose scale recover sooner than others from the effects of scalecidal sprays. In California stone fruit orchards, especially prune orchards, sprays applied during fall or winter have, in numerous instances, failed to hold infestations adequately in check during the subsequent growing season.
One of the most conclusive experiments completed to date is summarized in table 12. The situation involved prime prune trees on which the scale infestation had developed within two seasons into an almost complete incrustation on the major branches. A substantial amount of sampling by the twin-strip method showed 98 to 99 per cent reduc- 
tion in numbers of living scales 81 days after sprays were applied in the early dormant period. The very small differences between the samples of scales from the sprayed plots were not significant. The data obtained from the experiment were provisionally accepted as evidence of excellent control with two equally effective sprays. Actually, however, the control of the infestation lapsed during late summer. Within six months after the sampling operations (March 23), the survivors had regenerated a devastating population, sufficient to incrust and wilt near-ripe prunes and to cause extensive twig die-back. During this final inspection, we attempted to determine whether reinfestation varied according to the insecticide applied. We found that regeneration of the scale population was uniform throughout the experimental block.

The experiments summarized in tables 4, 6, and 11 illustrate cases in which winter sprays in peach orchards produced excellent results in initial scale reduction. In each case, however, the survivors regenerated damaging infestations before the growing season ended.

One of the critical factors in population recovery is number of survivors. The annual-twig method of appraisal does not show how numbers of survivors, per cent kill, effects of natural enemies, and other environmental factors act together to produce the results observed. Nevertheless, this method may give the most useful information about the outcome of control operations. Data from the annual-twig method may be considered as factors representing the total population of live scales on the trees. This population presumably arises from descendants of survivors of the treatments. If the data obtained earlier in the season by selective-count and matched-strip methods may also be considered as factors representing the total numbers of live scales on the trees, then there should be a correlation between these data and the data obtained later by the annual-twig method. Thus the earlier data should indicate the degree of subsequent population recovery.

When the per cent change between pre- and post-treatment counts of scales on annual-twig samples (table 6, IV) was compared with total numbers of survivors observed in selective counts (II) or on matched strips (III), the same trend was noticed. Scales increased on twigs from trees showing the largest numbers of survivors shortly after treatment, and decreased on twigs from trees showing the lowest numbers of survivors. The correlation between methods III and IV was possibly better than between methods II and IV. The values obtained by the matched-strip method (III) may have correlated more closely with the annual-twig data (IV) because the matched-strip procedure measured numbers of survivors per unit of bark surface-a unit which may better represent the total scale-producing area of each tree. The selective counts, as obtained by method I, do not define any particular scale-producing area. Unfortunately, the numbers of survivors on bark removed in the matched-strip samples were determined from parts of the trees most thoroughly covered by sprays (see page 16). The differences between trees or treatments as obtained from matched-strip samples tend to be quite small, but these small differences may indicate that large differences are to be expected in the annual-twig samplings. In this respect, the small differences observed between matched-strip samples may prove to be very significant.

When the dormant sprays listed in table 11 were appraised by the annualtwig method, the degree of population recovery within 11 months showed an inverse relation to initial levels of infestation. The 90 trees involved in the experiment were initially sorted into single-tree plots as described on page 17 . In the spray trials each tree within a treatment represented a different class group with respect to initial infestation and, conversely, each class group was composed of one tree of each treatment. 
When the pre- and post-treatment counts for the 90 trees were compared by group-without regard to kind of spray applied-the trees with highest pretreatment counts tended to show the highest per cent of scale reduction. As pretreatment counts diminished, the post-treatment counts increased, until they finally exceeded those for the pretreatments. Scale increase was greatest on trees having the lowest pretreatment counts (table 13 and fig. 1A).

In table 13 , the pretreatment counts were rearranged into six class groups of 15 trees each, so that one tree from each spray treatment was represented in each of the class groups. The post-treatment counts were computed from the group averages.

Another part of this same peach orchard was used for a different experiment (table 6 ), in which pre- and posttreatment counts of scales on annual twigs were available for each tree, but the pretreatment counts were not used in the same manner for assigning trees to the various treatments. To see if the data from this second experiment showed the same trend as the data in table 13, we placed the trees in the same

TABLE 13

INFLUENCE OF PRETREATMENT

INFESTATION ON NUMBER OF SAN JOSE SCALES ON TWIGS ELEVEN

MONTHS AFTER PRETREATMENT COUNTS, NINE MONTHS AFTER TREATMENT

\begin{tabular}{|c|c|c|c|}
\hline \multirow{2}{*}{ Group range } & \multicolumn{2}{|c|}{$\begin{array}{l}\text { Average number } \\
\text { of scales per tree* }\end{array}$} & \multirow{2}{*}{$\begin{array}{l}\text { Per cent } \\
\text { reduction } \dagger\end{array}$} \\
\hline & $\begin{array}{c}\text { Pre- } \\
\text { treatment } \\
\text { average }\end{array}$ & $\begin{array}{c}\text { Post- } \\
\text { treatment } \\
\text { average }\end{array}$ & \\
\hline $5,150-15,850$ & 8,140 & 2,285 & 72.0 \\
\hline $2,900-4,900$ & 3,659 & 1,695 & 55.3 \\
\hline $2,003-2,800$ & 2,405 & 1,626 & 31.9 \\
\hline $1,135-2,000$ & 1,495 & 1,756 & -17.4 \\
\hline $657-1,052$ & 865 & 2,104 & -144.2 \\
\hline $190-\quad 657$ & 423 & 1,892 & -347.0 \\
\hline
\end{tabular}

* Trees segregated into 6 groups according to pretreatment counts. Each group contained 15 trees, each of which received a different dormant spray. The same spray treatments were used in each group. Counts made on 5 twigs per tree, 10 internodes per twig.

t See Equation (4), p. 15. initial infestation groups. In the resulting arrangement many of the groups contained more than one tree for each treatment. To adjust for this inequality, the averages of the pre- and post-treatment counts for all the trees of the same treatment within any initial infestation group were used to calculate the means for all the treatments in the group. The results of the regrouping of the data from the second experiment are summarized in table 14 and are shown graphically in figure $1 \mathrm{~B}$. Both experiments showed the same influence of pretreatment counts (indices of initial infestation) on post-treatment counts of scales on twigs after dormant spray treatments.

The trend shown in figure 1 was also noted in the data from six trees sprayed with the same treatment on May 11, 1960 (table 11, last entry) - that is, as the initial infestation decreased, the post-treatment counts showed lower per cent reductions. This trend is shown in figure 2, A. The original annual-twig data summarized in table 9 were also grouped according to degree of initial infestation and again the trend was evident (fig. 2, B).

\section{TABLE 14}

INFLUENCE OF PRETREATMENT INFESTATION ON NUMBER OF SAN JOSE SCALES ON TWIGS ELEVEN MONTHS AFTER PRETREATMENT COUNTS, NINE MONTHS AFTER TREATMENT

\begin{tabular}{c|c|c|c}
\hline \hline & \multicolumn{2}{|c|}{$\begin{array}{c}\text { Average number } \\
\text { of scales per tree* }\end{array}$} & \\
\cline { 2 - 3 } Group range & $\begin{array}{c}\text { Pre- } \\
\text { treatment } \\
\text { average }\end{array}$ & $\begin{array}{c}\text { Per cent } \\
\text { treatment } \\
\text { average }\end{array}$ & \\
\cline { 2 - 3 } & reduction & \\
\hline $5,150-15,850$ & 6,917 & 2,862 & 58.7 \\
$2,900-4,900$ & 3,842 & 2,207 & 42.6 \\
$2,003-2,800$ & 2,308 & 1,548 & 33.0 \\
$1,135-2,000$ & 1,572 & 1,954 & -24.3 \\
$651-1,052$ & 876 & 2,285 & -160.0 \\
$190-657$ & 460 & 2,602 & -466.0 \\
\hline
\end{tabular}

* Trees segregated into 6 groups according to pretreatment counts. Each group contained a variable number of trees, but each treatment was represented in each group. Counts made on 5 twigs per tree, 10 internodes per twig.

$\dagger$ See Equation (4), p. 15. 


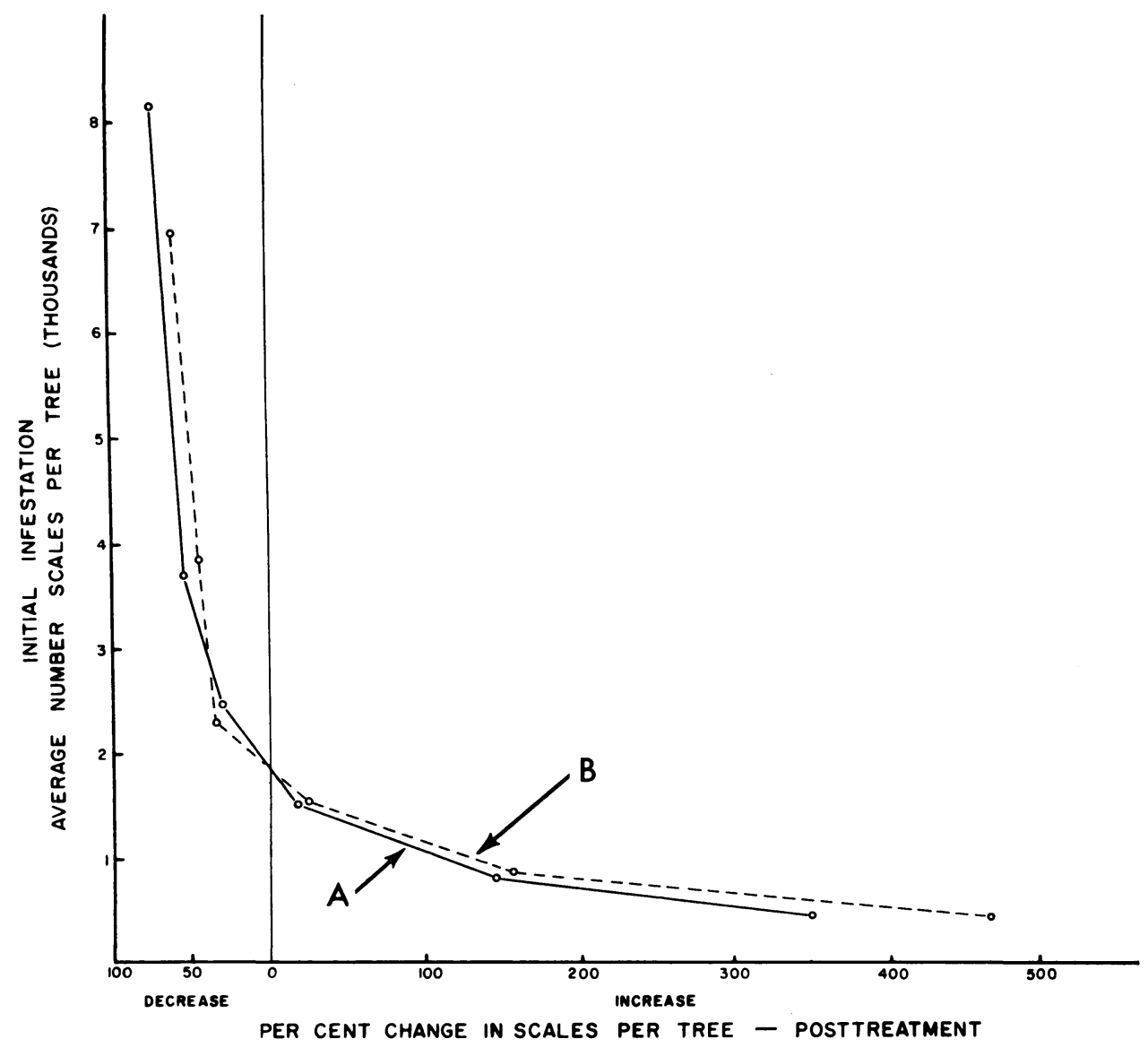

Fig. 1. Influence of initial infestation on per cent change in scales per tree after dormant spray treatment. A, each initial infestation group contained 15 trees, each of which received a different spray treatment; B, each initial infestation group contained a variable number of trees, but each treatment was represented in each group.

Figures 1 and 2 also indicate the greater effectiveness of spring sprays as compared with dormant sprays. In figure 1, trees of low initial infestation that received dormant sprays showed subsequent increases in infestation, while similar trees that received spring sprays (fig. 2) later showed only decreases in infestation.

The following is offered as a possible explanation for the influence of degree of initial infestation on control, and for consideration by those planning future experiments on control of San Jose scale.

High scale populations may so weaken trees that they become unsuitable for rapid reproduction of scales. Even after a high percentage of reduction following treatment, scales on weakened trees may increase at a reduced rate. The actual numbers of survivors on treated trees of very high initial infestation may also be great enough to attract natural enemies that help prevent recovery of the scales to their former density. At somewhat lower initial infestation levels, trees may not be so weakened. After treatment, a balance between host conditions favorable for scale increase and enough survivors to attract natural enemies may result in the same degree of infestation at the end of the growing season as was found before treatment. 


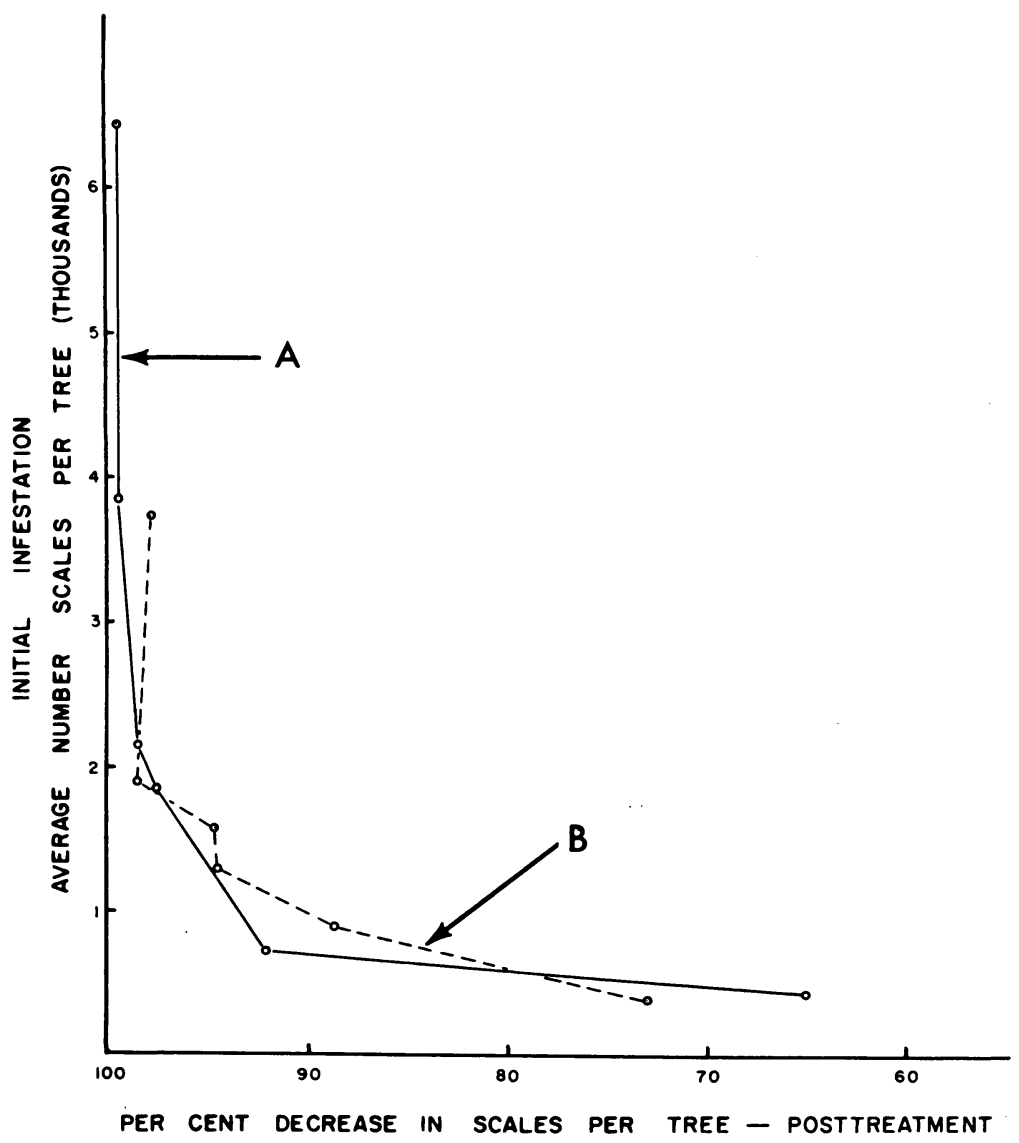

Fig. 2. Influence of initial infestation on per cent change in scales per tree after spring sprays. A, six trees sprayed with carbophenothion and oil in May, 1960 ; B, each initial infestation group contained nine trees, each of which received a different spray treatment.

With trees of still lower infestation, the population density after treatment may be so low that natural enemies are not attracted to the trees. Increase of scales in the as yet undamaged trees under these conditions may be very rapid, resulting in an increase in scales on twigs by the end of the growing season.

Previously applied sprays-such as in all tests reported here-may contribute to this influence of degree of initial infestation. Control may tend to concentrate survivors on the trees in places that are difficult to hit with sprays. Thus on trees where the infestation is light, a greater percentage of the living scales might be found in such protected places. The next spray would result in a lower percentage reduction of the scales on those trees than would the same spray on a heavily infested tree on which a greater portion of the population was exposed and easily controlled.

It should be noted that all of the data presented here on effect of degree of initial infestation on scale recovery after spray treatment were obtained from one young, vigorous peach orchard. Although the trends noted above were consistent, in a different, perhaps less vigorous, orchard the same influences of degree of initial infestation on spray control might not be apparent. 


\section{DISCUSSION AND CONCLUSIONS}

The experiments described did not result in a final, set procedure for determining how well certain sprays control San Jose scale or for distinguishing unerringly between materials and dosages. They did, however, point up some of the elements involved in a problem of this kind.

Host trees that show heavy incrustations of scale covers and even impressive symptoms of debilitation may not actually have vigorously thriving populations of the pest when selected for experimentation. Many of the data recorded during early phases of the project (not included here) are of dubious value because later experiences revealed that they were based on trials involving "static" or "regressive" infestations. Trees on which the bark of main limbs is relatively thin and smooth, and which have a predominance of actively feeding, immature scale insects are most desirable for test purpose. Infestations of this sort are likely to recover rapidly when treatment effects wear out.

The density of scale populations at the time of treatment apparently affects recovery potential. It is suspected that, with all scale insects, a spray that does not kill every individual will result in larger percentages of survivors as infestations of higher density are treated. One explanation for such a trend might be that the poison deposited must be divided among a greater number of scales in a densely populated area. Assuming normal survivors, a greater number of progeny would be expected from such a treated population (Barnes and Stafford, 1949). Another, and contrasting, effect of initial density on outcome of control was noticed here for the first time. Analyses of raw data from recent experiments show that, on lightly infested host trees sprayed before the period of scale reproduction begins, the scales regenerate proportionately heavier populations during the growing season than do trees that are more heav- ily infested when sprayed. Although the factors which regulate scale regeneration are scarcely understood at present, the effects of variation in initial pest density on control outcome can be minimized by employing pretreatment counts. Trees are assigned to treatments so that the averages of such counts for the trees in each treatment are more nearly uniform than when trees are assigned to treatments at random. One practical scheme for sorting trees into plots is described under "Methods," pp. 16-17.

Within the range of materials and dosages tried, "progressive" infestations of San Jose scale on prune and peach trees did not regenerate so extensively throughout the growing season when sprayed during May as when sprayed during fall or winter.

Winter sprays combining oil and insecticides have been valuable because the amount of oil may be reduced, and oil injury to trees avoided. However, sprays containing only dormant oil emulsion at the rate of 4 gallons per 100 gallons of water have been as effective as any of the oil-insecticide sprays tested. It has not been possible to show conclusively any differences among a number of insecticides used with oil in dormant or spring sprays. Such differences in effectiveness among insecticides as do exist will probably appear with the use of more refined testing methods.

A vital part of assessing control is deciding when to take the samples. Accumulated data do not encourage the notion that the interim between spraying and once-over sampling should be fixed by rule or generalization. Each situation has its own peculiarities with respect to weather, kind of test material, season of spraying and, possibly, host vigor.

Two parameters of population change are needed: one for degree and one for trend. The several sampling methods employed in this work provide useful 
information about degree of change, but none adequately reveals trend of change unless a sequence of samples is taken during the post-treatment period. In that case, the decision about when to sample is less critical because plot evaluation is not based on a single round of samples.

The combining of sampling methods, as shown in tables 6 and 9, appears to provide a practical means for evaluating control. The writers believe that a combination of selective counts and annual-twig counts, as carried out in one of the final experiments (table 9), points the way to more refined research on testing of sprays.

\section{ACKNOWLEDGMENTS}

Acknowledgment is made to Hiroshi Kido and Douglas W. Price, Department of Entomology, Davis, for help in the various field experiments. M. M. Barnes and G. E. Carman, Department of Entomology, Riverside, P. S. Messenger, Department of Entomology and Parasitology, Berkeley, and H. E. Thompson, Kansas State University, were kind enough to read and comment on the original manuscript. Among the many who also gave us valuable assistance are: Curtis A. Ferris, Arthur H. Retan, Norman W. Ross, and Ross R. Sanborn of the Agricultural Extension Service, and William H. Wade of the Niagara Chemical Division, Food Machinery and Chemical Corporation.

\section{LITERATURE CITED}

ANThon, E. W.

1960. Insecticidal control of San Jose scale on stone fruits. Jour. Econ. Ent. 53(6):1085-87.

BARNes, D. F., and E. M. STAFFord

1949. Control of fig scale in California. Jour. Econ. Ent. 42(1):48-55.

Carman, G. E.

1956. Field evaluation of malathion for control of California red scale on citrus. Jour. Econ. Ent. $49(1): 103-11$.

EBELING, WALTER

1947. DDT preparations to control certain scale insects on citrus. Jour. Econ. Ent. $40(5)$ : 619-32.

Gentile, A. G., and F. M. Summers

1958. The biology of San Jose scale on peaches with special reference to the behavior of males and juveniles. Hilgardia $27(10): 269-85$.

O'NEILL, W. J.

1951. DDT and parathion for San Jose scale control. Jour. Econ. Ent. 44(5):709-11.

Snapp, O. I., and J. R. Thomson, JR.

1943. Experiments with oils and lime sulfur for the control of the San Jose scale on peach trees in the South. U. S. Dept. Agr. Tech. Bul. 852:1-12.

STAFFoRD, E. M.

1954. Use of parathion to control olive scale. Jour. Econ. Ent. 47(2):287-95.

Thompson, H. E.

1962. European elm scale investigations. Jour. Econ. Ent. 55(4):430-34.

In our publications it is sometimes convenient to use trade names of products or equipment rather than scientific identifications. In so doing it is unavoidable in some cases that similar products which are on the market under other trade names may not be cited. No endorsement of named products is intended nor is criticism implied of similar products which are not mentioned. 
The journal HILGARDIA is published at irregular intervals, in volumes of about 650 to 700 pages. The number of issues per volume varies.

Single copies of any issue may be obtained free, as long as the supply lasts; please request by volume and issue number from:

\author{
Agricultural Publications \\ University Hall \\ University of California \\ Berkeley 4, California
}

The limit to nonresidents of California is 10 separate titles. The limit to California residents is $\mathbf{2 0}$ separate titles.

The journal will be sent regularly to libraries, schools, or institutions in one of the following ways:

1. In exchange for similar published material on research.

2. As a gift to qualified repository libraries only.

3. On a subscription basis $-\$ 7.50$ a year paid in advance. All subscriptions will be started with the first number issued during a calendar year. Subscribers starting during any given year will be sent back numbers to the first of that year and will be billed for the ensuing year the following January. Make checks or money orders payable to The Regents of The University of California; send payment with order to Agricultural Publications at above address. 